\title{
Case selection by a limnephilid caddisfly [Potamophylax latipennis (Curtis)] in response to different predators
}

Received: 12 May 2005 / Revised: 23 May 2005 / Accepted: 25 July 2005 / Published online: 29 September 2005

(C) Springer-Verlag 2005

\begin{abstract}
Some organisms use morphological structures obtained by behavioural processes to lower mortality by predation. We test whether larvae of the limnephilid caddisfly Potamophylax latipennis (Curtis) vary their responses to the presence of different predators (dragonfly naiads, fire salamander larvae or brown trout) by choosing organic or mineral cases. We offered both case types to larvae, and simulated differences in predation risk using water conditioned with chemicals from the different predators. Our results show that Potamophylax larvae detect and discriminate predators using water-borne chemical cues and alter their choice of case type according to the perceived predation risk. Moreover, the distribution of larvae bearing cases of different anti-predator value matches the spatial variation in predation risk in the field.
\end{abstract}

Keywords Behaviour Predation risk - Inducible defences $\cdot$ Trichoptera

\section{Introduction}

Diverse prey organisms exhibit responses in the form of changes in their morphology when exposed to predator cues (Harvell 1984; Lively 1986; Dodson 1989; Brönmark and Miner 1992; Relyea 2001; Trusell and Nicklin 2002). Predator-induced morphologies benefit prey by reducing predation risk, but also entail fitness costs that prevents their becoming permanent (Tollrian and Harvell 1999; Petterson and Brönmark 1999; Van Buskirk 2000). Prey

Communicated by G. Wilkinson

L. Boyero $(\bowtie) \cdot$ P. A. Rincón · J. Bosch

Museo Nacional de Ciencias Naturales (CSIC),

Madrid, Spain

L. Boyero

School of Tropical Biology, James Cook University,

Townsville, Queensland, 4810, Australia

e-mail: luz.boyero@jcu.edu.au

Tel.: +61-7-47814548

Fax: +61-7-47251570 organisms can show predator-specific morphological shifts (Relyea 2001) along with co-varying behavioural traits (Van Buskirk and McCollum 2000). However, a direct influence of behaviour on the expression of morphological defences is uncommon (McCollum and Leimberger 1997).

Some animals, such as cased caddisfly larvae and hermit crabs, decrease predation risk through the use of exogenous materials to cover the softer, more vulnerable parts of their bodies (Otto and Svensson 1980; Johansson 1991; Conover 1978; Borjesson and Szelistowski 1989; Cote et al. 1998). This phenomenon represents an interesting interface between morphology and behaviour, as behavioural processes yield what could be functionally regarded as morphological structures (Nislow and Molles 1993). Hermit crabs use empty gastropod shells whose transportation is energetically costly (Herreid and Full 1986). Caddisfly larvae construct their own cases from organic or mineral particles cemented with silk that they secrete, incurring costs in both transport (Otto 2000) and construction, as the silk employed can be a substantial part of the total energy content of the larvae (Otto 1974; Stevens et al. 1999).

Some stream-dwelling caddisfly larvae of the family Limnephilidae show polymorphism in case material, with some individuals building an organic case and others a mineral case (Molles and Nislow 1991; Nislow and Molles 1993; Otto and Svensson 1980). This variability is partly ontogenetic (Otto and Svensson 1980), but it may also be due to variation in predation risk, that is, individuals could use different materials to build the case depending on the presence or absence of predators. Mineral cases are usually heavier than organic ones and composed of more pieces, so they are more costly to carry and build (Otto and Svensson 1980; Stevens et al. 1999; Otto 2000), but they usually withstand predator attacks more efficiently due to a greater resistance to crushing (Nislow and Molles 1993; Otto and Svensson 1980).

There is some evidence that indicates that case polymorphism in limnephilid larvae may be related to predation risk. For example, Molles and Nislow (1991) reported that larvae of Hesperophylax magnus (Banks) built stronger cases after exposure to a predatory stonefly. However, the 
extent to which behavioural responses modulate case polymorphism in limnephilid larvae needs to be investigated in detail. This system provides a valuable opportunity to explore whether producing "morphology" rather than "behaviour" has any effect upon the expression of behavioural anti-predator responses. Behavioural traits are usually more plastic than morphological ones (WestEberhard 1989; Relyea 2001), but a behaviour that results in morphological changes should show reduced plasticity. Caddisfly cases can be viewed as intermediate between behavioural responses to predators (e.g. drift behaviour in mayflies; McIntosh et al. 2002) and plastic morphological defences (Harvell 1990).

In this study, we experimentally tested if variation in perceived predation risk determines changes in a morphological structure (the case) mediated by individual behaviour (selection of cases of different materials) in the larvae of Potamophylax latipennis (Curtis), a limnephilid caddisfly that exhibits case polymorphism in montane streams in Central Spain and elsewhere. Additionally, we assessed whether the distribution patterns of the two case types in the field match the spatial variation in predation risk.

\section{Materials and methods}

Natural history

Potamophylax latipennis (hereafter Potamophylax) larvae are abundant in the streams of Peñalara Natural Park (Sierra de Guadarrama, Madrid, Central Spain) and exhibit case polymorphism. Larvae with organic cases, composed of sticks and leaf fragments, coexist with larvae inhabiting mineral cases made of sand grains. Some individuals even add cases of sericostomatid caddisfly larvae to their own mineral cases (Boyero and Barnard 2003). Individuals with both organic and mineral cases are found side by side (personal observation).

Potential predators of Potamophylax in those streams include brown trout (Salmo trutta L), larvae of the fire salamander (Salamandra salamandra L) and dragonfly (Cordulegaster boltonii Donovan) naiads. Salamander larvae and $C$. boltonii naiads are widespread, whereas brown trout are absent from headwater reaches due to barriers to upstream dispersal. Hence, Potamophylax larvae plausibly experience spatial variation in predation risk.

Previous studies have shown that the mineral cases of the genus Potamophylax and other limnephilids are of greater defensive value than organic ones against brown trout and dragonflies that rely on crushing or puncturing the case for successful predation (Otto and Svensson 1980; Johansson 1991; Otto and Johansson 1995; Nislow and Molles 1993). Gut content analyses have revealed that brown trout eat larvae of Potamophylax and other limnephilids with their cases (Rincón 1993). C. boltonii has been observed to feed on Potamophylax larvae in the laboratory (personal observation). We have not observed C. boltonii feeding on Potamophylax in the field, but Woodward and Hildrew (2002) showed that Potamophylax cingulatus was part of its diet. Pilot trials (see below) indicated that larvae of the fire salamander are very efficient predators of caseless Potamophylax larvae, but also that they apparently need to separate the larvae from its case to consume it and that organic cases seem to offer as much protection as mineral ones. This agrees well with existing information on predation by some North American salamander species on limnephilid larvae (Wissinger et al. 1999; Holomuzki 1983).

Pilot trials on predation on Potamophylax by $S$. salamandra

Five $S$. salamandra larvae were captured in a second-order stream and individually held in 5-1 plastic containers filled with 41 of stream water and partially submerged in the stream. The salamanders were allowed to acclimate for $1 \mathrm{~h}$, and then two Potamophylax larvae with mineral cases were introduced into each container. After $1.5 \mathrm{~h}$, we inspected the containers, and all 10 caddisfly larvae were found alive. They were removed and substituted by an equal number of similarly-sized Potamophylax larvae with organic cases. We checked the containers again once another $1.5 \mathrm{~h}$ elapsed, and all 10 larvae were also recovered. We replaced them with 10 caseless larvae (one originally inhabiting a mineral case and one an organic case per container) and after a final $1.5 \mathrm{~h}$, we only found three caddisfly larvae remaining. From these data, we concluded that differences in case material and design probably have little influence on the vulnerability of Potamophylax larvae to fire salamander larvae, but that having a case of whatever type determines the likelihood of survival of Potamophylax in encounters with salamander larvae.

\section{Experimental animals}

Potamophylax larvae, with organic and mineral cases, were collected in May and June 2003 from a second-order reach of the Arroyo de Pepe Hernando that flows through alpine meadows at approximately $1,870 \mathrm{~m}$ above sea level. The Arroyo de Pepe Hernando is a tributary of Peñalara stream, a mountain stream flowing in the Peñalara Natural Park $\left(40^{\circ} 50^{\prime} \mathrm{N}, 3^{\circ} 57^{\prime} \mathrm{W}\right)$. At collection, water temperature ranged between $12.5-16.0^{\circ} \mathrm{C}$ and air temperature between $17.8-25.0^{\circ} \mathrm{C}$. All the individuals were captured with softtipped forceps at current velocities of $10-40 \mathrm{~cm} \mathrm{~s}^{-1}$ on different substrates (cobbles, gravel, sand, silt and coarse organic matter). All three types of predators (trout, dragonfly naiads and salamander larvae) were present at the collection reach.

After collection, Potamophylax larvae were transported in a box with ice to the laboratory, where they were acclimatised for at least $24 \mathrm{~h}$ before being used in the experiment. For acclimatisation, larvae were placed in transparent plastic containers $(115 \mathrm{~mm}$ diameter, $45 \mathrm{~mm}$ height) with a 10-mm layer of organic-matter-free commercial siliceous sand on the bottom (sand grains of 2 
$5 \mathrm{~mm}$ diameter) and filled with dechlorinated tap water $(200 \mathrm{ml})$ and stream water $(100 \mathrm{ml})$. The containers were closed and aerated with an air stone. Thirty-six of these containers were used for the experiments, but they were now filled with $300 \mathrm{ml}$ of dechlorinated tap water, and each one received a single Potamophylax larva. At all times, individuals were provided with air-dried alder (Alnus glutinosa) leaves ad libitum.

\section{Preparation of stimuli}

To simulate differences in predation risk, we used water conditioned with chemicals from each of the three different predators. Dragonfly naiads (Cordulegaster sp.) were obtained from the same reach where Potamophylax larvae were collected, taken to the laboratory and kept individually in plastic containers $(115 \mathrm{~mm}$ diameter and $45 \mathrm{~mm}$ height) filled with $300 \mathrm{ml}$ of dechlorinated tap water for 10-14 h. After this period, the naiads were returned to the stream, and the water was filtered through glass wool and divided into $15-\mathrm{ml}$ aliquots, which were immediately frozen and stored at $-4^{\circ} \mathrm{C}$ for subsequent use.

Three brown trout (12, 14 and $18 \mathrm{~cm}$ fork length) were captured with a backpack electroshocker in the Arroyo de Pepe Hernando. They were then maintained for $3 \mathrm{~h}$ in a 40-1 plastic container partially submerged in the stream and filled with 301 of water from the fishless upstream section. The trout were subsequently released back into the stream, and 51 of the conditioned water thus obtained was stored in plastic bottles, taken to the laboratory and treated as described for dragonfly naiads.

Salamander larvae were obtained from the fishless section of the Arroyo de Pepe Hernando and kept for $3 \mathrm{~h}$ in 51 plastic containers (three larvae per container) filled with water from the fishless section of the stream. After this period, the larvae were released into the stream, and the conditioned water was processed as described for trout.

Additionally, 51 of dechlorinated tap water were filtered through glass wool and distributed into $15 \mathrm{ml}$ aliquots. Those were subsequently frozen and stored to be used as control (no predator chemicals).

\section{Experiment}

To assess the effect of differences in perceived predation risk upon case selection by Potamophylax larvae, we presented three organic and three mineral cases to uncased larvae under treatments that simulated the presence of different predators. The treatments were: (a) no predator odour, (b) dragonfly naiads odour, (c) salamander larvae odour and (d) brown trout odour. All these predators are potential natural predators for Potamophylax in montane streams in Central Spain and elsewhere. However, they differ in their abundance and their hunting techniques and thus pose different types and intensities of predation threats.
Only larvae whose cases were composed of over $80 \%$ of either organic or mineral materials (visual estimation) were used in the experiments. Potamophylax larvae were removed from their cases by gently pushing them from the posterior end of the case with soft-tipped forceps, and the type of the original case was noted. Individuals that originally had an organic/mineral case will hereafter be called "organic individuals/mineral individuals". Each uncased larva and three mineral and three organic cases were placed in a container. Those cases were obtained from the experimental larvae, plus additional individuals collected at the same sites. The cases presented to each larva were visually similar in size to the original case of each experimental subject, but each individual was never offered its own former case.

Once the larva and the six cases had been placed in it, each container was randomly assigned to one of the experimental treatments and immediately received $5 \mathrm{ml}$ of either control or water containing the corresponding stimulus. This procedure was repeated every $12 \mathrm{~h}$. For their use in the experiment, the required volumes of predatorconditioned and control water were extracted from the freezer in advance, allowed to thaw to ambient temperature, and then introduced into the experimental arenas with a syringe. The number of larvae in each experimental group ranged from 16 to 24 .

Potamophylax larvae were monitored twice per day. When a larva entered a case, it was removed from it and placed again in the container for another trial until it completed four repetitions. On each repetition, the selected case type (organic or mineral) was recorded, and the selected case was removed and replaced by a new one of the same type and similar size. In this way, we sought to avoid that the particular features of a given case (e.g. better fit), rather than those of a case type, determined case choice. Once an individual had performed four choices, it was euthanized and preserved in $70 \%$ ethanol to subsequently estimate its size by measuring the width of its head ( $\mathrm{HW}$, in $\mathrm{mm}$ ) under a binocular microscope $(10 \times)$ equipped with a micrometer ocular. Besides the case type selected, we noted the time elapsed until a choice was made as follows: "day 0" if selection occurred within $24 \mathrm{~h}$ from the beginning of the trial, "day 1" if it happened in the following $24 \mathrm{~h}$, etc.

\section{Field censuses}

To assess whether the spatial variation in the relative abundance of Potamophylax larvae with cases of different types matched changes in predation risk, we conducted visual censuses in reaches of the Arroyo de Pepe Hernando containing different predator assemblages. Specifically, we estimated the abundance of Potamophylax larvae in $20 \times 20$ $\mathrm{cm}$ quadrats distributed along approximately $150 \mathrm{~m}$ of bank length both upstream and downstream of a waterfall, above which brown trout were absent. All three predators were present below the waterfall, but salamander larvae are in much lower numbers than above it. Visual censuses conducted in the summer of 2002 in the Arroyo de Pepe 
Hernando showed that the average density of salamander larvae below the waterfall was 0.025 inds. $\mathrm{m}^{-2}$ vs 0.140 inds. $\mathrm{m}^{-2}$ above it. Surber samples taken also in the summer of 2002 revealed no variation in the abundance of dragonfly naiads above and below the waterfall (L. Boyero, unpublished data).

Potamophylax larvae counts were carried out from 11 a. $\mathrm{m}$. to $4 \mathrm{p}$.m. from the 7 th to the 21 st of July 2003 . We obtained 100 counts above the waterfall and 82 below. Observations were made with the aid of a translucent plastic box with a $20 \times 20-\mathrm{cm}$ glass window on its bottom (following Allan et al. 1986) and supported by four metal legs whose height could be adjusted. We set the box 10 $15 \mathrm{~cm}$ above the bottom of the stream, and an observer remained motionless by its side for $10 \mathrm{~min}$. Then, the observer counted the number of Potamophylax larvae with mineral or organic cases visible within the $20 \times 20 \mathrm{~cm}$ quadrat. Only larvae with cases made up of $80 \%$ or more of either mineral or organic matter were included in analyses. Pilot trials showed that the setting of the box caused very little disturbance to Potamophylax larvae and that they always resumed apparently normal behaviour (crawling on the bottom, feeding) within less than 5 min.

\section{Data analysis}

\section{Variables}

We used three metrics to describe the response of $P_{O}$ tamophylax larvae in the experiment: preference, consistency of choice and response time.

Preference was arbitrarily defined as the preference for mineral cases and was calculated for each individual as the proportion of mineral cases chosen. It could range from 0 (no mineral case was ever used) to 1 (all four choices were of a mineral case).

Consistency of choice measured the degree to which an individual consistently selected a given case type. We calculated the proportion of mineral and organic case selections, and the greater of the two was the consistency of choice for each individual. It could range from 0.5 to 1 , with higher values indicating greater consistency in case choice.

Response time was measured as explained above, and the average response time of the four repetitions was calculated for each individual and used in subsequent analyses.

\section{Statistical analyses}

To test whether the observed preference and consistency of choice for each predation treatment $\times$ original case combination could be considered the result of active case selection, we estimated the probability of obtaining those values under conditions of random choice. For each treatment $\times$ case group, we calculated the average values for preference and consistency of choice. Then, we constructed a simulated group of the same number of larvae, simulated four random choices (i.e. equal probability of selecting an organic or mineral case on each repetition) per individual and calculated the corresponding average values of preference and consistency of choice for the simulated group. We repeated this procedure 10,000 times for each group and stored the average values thus obtained. Then, we calculated the grand mean of the 10,000 repetitions and checked whether this value was smaller or greater than the corresponding observed one. If the grand mean of the simulated values was smaller than the observed value, we next tallied how many of the 10,000 simulated average values were greater than the observed one. Otherwise, we counted the number of simulated values that were below the observed one. Then, we divided that figure by 10,000 to estimate the probability that the observed value was a product of purely random choice, and, if it was smaller than 0.05 , we concluded that the observed preference or consistency of choice were caused by active selection.

We tested for differences in preference, consistency of choice and response time among predation treatment $x$ original case combinations with a full factorial, two-way analysis of covariance (ANCOVA). Predation treatment and original case type were the major factors, and HW was the covariate. Preliminary analyses showed that there were no significant interactions between the categorical factors and the covariate $\left(F_{3,132}=2.31-0.68, P>0.05 ; F_{1},{ }_{132}=2.42\right.$ $0.19, P>0.05)$. Hence, interaction terms were removed, and we tested a common slope model. When the ANCOVA detected significant differences for one of the factors in the model, we used a posteriori Tukey tests to identify which groups of larvae (as defined by the treatments for that factor) were significantly different from each other.

The differences in the abundance of Potamophylax larvae (number of larvae per $400 \mathrm{~cm}^{2}$ ) with mineral or organic cases between stream sections with different predator assemblages were assessed with a full factorial, two-way analysis of variance (ANOVA). Case type and predator assemblage were the major factors. If the ANCOVA or ANOVA found significant differences, we performed a posteriori Tukey tests to identify those groups whose means differed significantly.

Consistency of choice and preference were square-root, arcsine transformed, while response time and the number of larvae were transformed to its decimal logarithms. The transformed variables exhibited no significant heteroscedasticity or deviation from normality (Bartlett and $\chi^{2}$ tests, $P>0.05$ in all cases). All results of statistical tests and the associated probabilities shown below are for the transformed variables. However, we have presented the untransformed values when we thought they would be more illustrative for the readers. Analyses were performed with the Statistica 6.0 package (StatSoft 2001).

\section{Results}

Case selection and consistency of choice

Individual Potamophylax larvae were consistent in their case choice. Average consistency of choice ranged from 

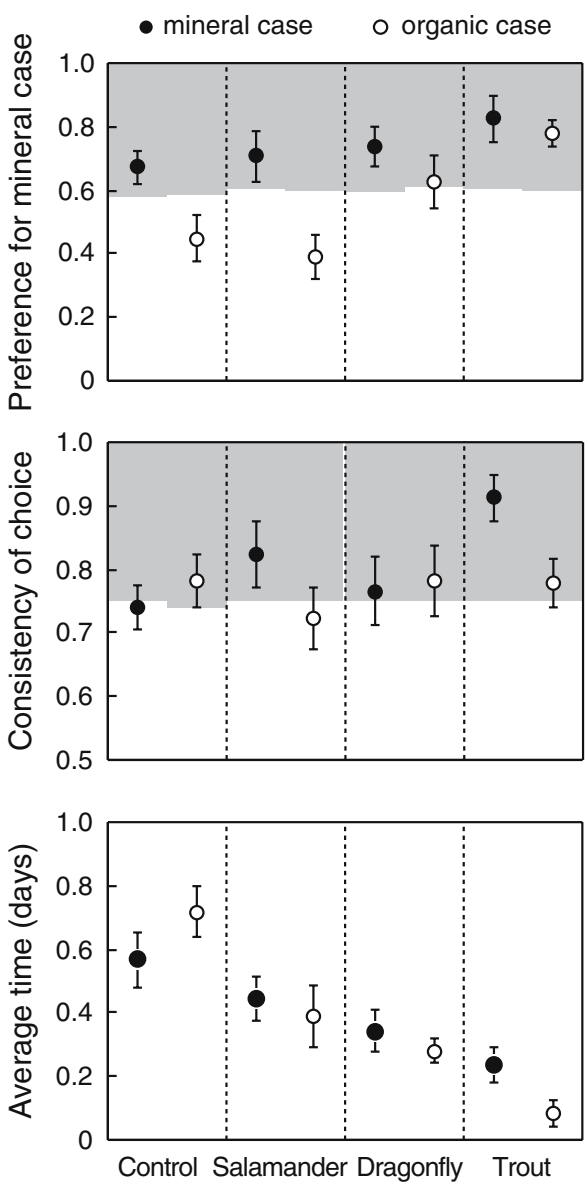

Fig. 1 Differences in preference for mineral case, consistency of choice and average response time between Potamophylax larvae with different original case type (mineral/organic) under different predation treatments (control or no predator odour/salamander odour/dragonfly odour/trout odour). Bars represent standard errors. The grey-filled area corresponds to values of preference for mineral cases and consistency of choice which are significantly different $(p<0.05)$ from those that random choice would have produced for each experimental group of larvae

0.72 to 0.91 , and only two groups out of eight (mineral/ control and organic/salamander) exhibited average consistency of choice values that were not significantly different from random (Fig. 1).

This high individual consistency in case selection generally resulted in clear preferences at the group level. The average proportion of mineral cases chosen varied between 0.39 and 0.82 , and seven out of the eight experimental groups displayed significant selection for (six groups) or against (one group, organic/salamander) mineral cases (Fig. 1). However, the individuals in the organic/ control group did not exhibit a significant average preference for or rejection of mineral cases, although they were highly consistent (i.e. selective) in their choices at the individual level. This pattern suggests that, under certain circumstances, Potamophylax larvae do exhibit case selection, but that their preferences are variable among individuals.
Differences between types of individuals and among treatments

Potamophylax larvae exhibited significant changes in their preference towards mineral cases and in the time they took to choose a case in response to variation in perceived predation risk mediated by water-borne chemical cues (Table 1). The preference for mineral cases increased in the dragonfly and trout treatments (Fig. 1). The latter was significantly greater than that of the control and salamander ones (Tukey test, $P=0.0018$ and $P=$ 0.0042 , respectively). Also, response time decreased in the order control $>$ salamander $>$ dragonfly $>$ trout (Fig. 1). Larvae that were not exposed to predator cues took significantly longer to enter a case than those in all predator treatments (Tukey test, $P<0.011$ in all cases). Additionally, larvae that received trout odour entered a case more rapidly than those exposed to salamander odour (Tukey test, $P=0.0012$ ).

Potamophylax larvae also showed significant variation in their case selection depending on their original case type (Table 1). Larvae that originally inhabited mineral cases subsequently showed a significantly greater preference for cases of the same type than larvae whose initial case was organic (Fig. 1).

Neither changes in predation risk nor the original case type had a significant effect on the individual consistency of case choice. Additionally, the effects of the original case type and of perceived predation risk were mutually independent, as the original case $\times$ predation treatment interaction was never significant. Similarly, there was no significant effect of HW upon any of the response variables (Table 1).

\section{Field distribution}

Variation in both the presence/abundance of different predators $\left(F_{1,178}=6.74, P=0.01\right)$ and in case type $\left(F_{1,178}=66.43\right.$, $P<0.0001)$ had a significant effect on the abundance of Potamophylax larvae in the field. Moreover, the two effects were not independent $\left(F_{1,178}=15.45, P=0.0001\right.$; Fig. 2). Thus, the abundance of Potamophylax larvae with mineral cases showed no significant changes above and below the waterfall that marked the limit of brown trout presence and the difference in salamander larvae abundance (Tukey test, $P=0.7800$ ). In contrast, the numbers of larvae using organic cases decreased markedly in the section of the stream inhabited by trout (Fig. 2, Tukey test, $P<0.0001$ ). Larvae with organic cases were, nonetheless, significantly more abundant than those with mineral cases both above and below the waterfall (Fig. 2, Tukey test, $P<0.0001$ above and $P<0.0220$ below), and their greater rarity below the waterfall resulted in a significant reduction of the overall abundance of Potamophylax larvae in that area (mean $\pm 95 \%$ CI above $=1.26 \pm 0.19$ inds. $\mathrm{cm}^{-2}$; below $=0.80 \pm 0.21$ inds. $\mathrm{cm}^{-2}$; Tukey test, $P=0.0095$ ). 
Table 1 Results of ANCOVA tests $(F$ statistics and associated degrees of freedom and probability values) for differences in behavioural metrics of case choice of Potamophylax larvae among predation treatments and original case type (covariate: head width)

\begin{tabular}{llrrr}
\hline Variable & Factor & \multicolumn{2}{l}{ df } & \multicolumn{2}{c}{$p$} \\
\hline Preference for mineral case & Predation & 5.46 & 3,139 & 0.0010 \\
& Case type & 4.63 & 1,139 & 0.0330 \\
& Predation $\times$ Case type & 1.30 & 3,139 & 0.2770 \\
Consistency of choice & Head width & 2.93 & 1,139 & 0.0890 \\
& Predation & 1.43 & 3,139 & 0.2350 \\
& Case type & 0.13 & 1,139 & 0.7160 \\
Response time & Predation $\times$ Case type & 1.68 & 3,139 & 0.1740 \\
& Head width & 2.86 & 1,139 & 0.0930 \\
& Predation & 16.85 & 3,139 & $<0.0001$ \\
& Case type & 0.60 & 1,139 & 0.4410 \\
& Predation $\times$ Case type & 1.86 & 3,139 & 0.1400 \\
& Head width & 0.00 & 1,139 & 0.9800
\end{tabular}

and Lefcort 1993; Dodson et al. 1994; Rittschof and Hazlett 1997; Wudkevich et al. 1997; Kats and Dill 1998; Summey and Mathis 1998; Chivers 1998; Huryn and Chivers 1999; Brönmark and Hansson 2000; McIntosh et al. 2002; Peckarsky et al. 2002). Responses to chemicals from fish and invertebrate predators, including changes in activity (Kuhara et al. 2001; Malmqvist 1992) and the building of stronger cases (Molles and Nislow 1991), have been reported for some caddisfly larvae. However, other studies have not detected any variation in activity (Wissinger et al. 1999; Kohler and McPeek 1989) or case construction (Otto 2000). Our design might have facilitated the expression of anti-predator responses by lowering their total cost through the removal of case construction costs. Furthermore, phylogenetic differences may have been relevant: the subjects of our study and that of Molles and Nislow (1991) (Limnephilidae) exhibit case polymorphism in nature, while the subjects in Otto (2000) (Goeriidae) do not seem to display any case polymorphism in the field.

\section{Discussion}

Our results show that: (1) Potamophylax larvae can assess predator presence and discriminate among different predators using water-borne chemical cues; (2) they modify their case choice behaviour according to differences in perceived predation risk; (3) individuals generally show consistent case selection and (4) the distribution of larvae bearing cases of different anti-predator values matches the spatial variation in predation risk in the field. These findings are discussed in more detail below.

\section{Chemical detection of predators}

Our results demonstrate that Potamophylax larvae can use chemical cues to detect and discriminate among three different predators, subsequently responding in different ways to them. Hence, water-borne predator chemicals appear to function as a reliable indicator of predation risk for $P_{O}$ tamophylax larvae and may, thus, facilitate the evolution of plastic responses (Harvell 1990).

The use of chemical cues to assess predation risk is widespread among aquatic organisms (Smith 1992; Wilson

\section{Case selection behaviour}

Cues from all three predators produced a marked reduction in the time that Potamophylax larvae were willing to spend without a case. This suggests that caseless Potamophylax larvae are more vulnerable than those with a case to the three predators to which they were exposed in our experiment, as has been suggested for $P$. cingulatus exposed to trout (Otto and Svensson 1980), Limnephilus frijole exposed to the cyprinid fish Gila robusta (Nislow and Molles 1993) and Limnephilus spp. exposed to Ambystoma tigrinum nebulosum (Holomuzki 1983).

Cues from dragonflies and trout elicited a marked increase in the preference for mineral cases, while cues from salamander larvae did not result in significant changes in case selection relative to control. This dissimilar pattern is consistent with the different hunting techniques of those predators. Dragonfly naiads and brown trout rely on physically damaging the case (puncturing, rupturing or crushing) for successful predation (personal observation), and mineral cases offer greater protection than organic ones against them (Otto and Svensson 1980; Johansson 1991; 
Nislow and Molles 1993; Johansson and Englund 1995). In contrast, fire salamander larvae need to separate the larvae from its case to consume it (see above), as shown for ambystomatid salamanders (Holomuzki 1983; Wissinger et al. 1999), and both organic and mineral cases seem to be of the same anti-predator value against them.

Furthermore, our findings suggest that a trade-off between the cost of carrying a case and its protective value may have influenced case selection by larvae. Mineral cases are heavier than organic ones in P. latipennis (personal observation), as occurs in P. cingulatus (Otto and Svensson 1980) and, therefore, they should be more costly to move (Otto 2000). Larvae showed an increased preference for mineral cases only when exposed to predators against which they should provide more protection, but not when mineral and organic cases were of similar protective value. Similar trade-offs between protection and transport costs have been reported to guide shell selection by hermit crabs (Conover 1978; Lively 1988; Borjesson and Szelistowski 1989; Wilber 1990; Mima et al. 2002).

Besides transport costs, case building also entails a substantial energetic expenditure (Stevens et al. 1999) that is usually greater for mineral than for organic cases (Otto and Svensson 1980) and that is likely to influence patterns of case polymorphism in the field (Otto and Svensson 1980). Our experimental design removed construction costs and, thus, presumably reduced the total cost of inhabiting a mineral case vs an organic one. While this design isolated the potential effects of transport costs, it may also have made a preference for mineral cases more likely. This situation may explain, for example, why some larvae that inhabited organic cases in the presence of predators in the field would occasionally choose mineral ones in the predator-free treatment in the laboratory. This bias may have actually facilitated our detection of chemical assessment of predation risk and flexible anti-predator responses in Potamophylax larvae. However, we are aware that it affects the applicability of our results to field situations to some extent.

Additionally, our offering already-built cases means that case fit, which we did not assess, may have also played a role in case choice besides protective value and cost of transport. Case fit is known to influence case selection in other case-bearing trichopteran larvae (Otto 1987; Englund and Otto 1991). In our situation, it may have accounted, for example, for the few instances of individuals with original mineral cases that chose organic ones in the trout treatment. Nevertheless, our major conclusions are not affected by the potential effects of either case fit or lowered overall cost of mineral cases.

Assessing the consistency of behaviour is relevant to understand its evolution, as differences among individuals must show a minimum degree of consistency for natural selection to act upon them (Boake 1994). Despite its importance, ours is one of relatively few studies that have actually measured the consistency of anti-predator responses. As in Dewitt et al. (1999) for an aquatic snail, we found that anti-predator responses in the form of case selection by Potamophylax larvae were typically consistent. The experimental time was relatively short (usually less than a week) and, therefore, changes in size, which may have promoted variation in case choice (Otto and Svensson 1980), were probably minor. In addition, we fed all individuals ad libitum during the acclimatisation period and throughout the experiment and, thus, probably reduced temporal changes in nutritional state, another potential source of behavioural variation.

\section{Spatial variation in case material in the field}

The total abundance of Potamophylax larvae and the relative abundance of mineral and organic individuals varied in the Arroyo de Pepe Hernando matching changes in the assemblage of potential predators. The abundance of organic larvae was markedly lower in the downstream section of the stream where trout were present. In contrast, the numbers of mineral larvae showed little variation between the areas with and without trout. Selective predation on larvae with cases of lower protective value may produce this pattern (Van Buskirk and McCollum 1999), but our results indicate that behavioural responses of Potamophylax larvae to trout chemical cues may also contribute to it. Certainly, the two mechanisms are not mutually exclusive, but we can currently offer no definitive insight on their relative importance.

\section{Conclusions}

We have shown that Potamophylax larvae can reliably detect and discriminate predators using water-borne chemical cues and that they alter their choice of case according to the perceived predation risk. Our findings suggest that case polymorphism in Potamophylax larvae, besides having an ontogenetic component, may be a plastic, morphological response subject to direct behavioural modulation. To demonstrate this phenomenon, however, further experiments should be conducted in which larvae are allowed to construct their case, rather than select one already constructed, in the presence of water-borne chemical cues from different predators. The behavioural control of a morphological defence appears to be a relatively rare phenomenon and seems restricted to organisms in which functionally morphological structures are used to lower predation mortality. Such systems should provide a fertile ground for the study of the relationships between behaviour and morphology.

Acknowledgements The first author is supported by a postdoctoral grant from the Secretaría de Estado de Educación y Universidades (MECD, Spain) co-financed by the European Social Fund. The second and third authors are supported by the Ramón y Cajal programme from the MCYT (Spain). Collecting permits were obtained from the Consejería de Medio Ambiente of the Comunidad de Madrid, Spain. The experiments comply with the current laws of Spain. 


\section{References}

Allan JD, Flecker AS, McClintock NL (1986) Diel epibenthic activity of mayfly nymphs, and its nonconcordance with behavioral drift. Limnol Oceanogr 31:1057-1065

Boake CRB (1994) Quantitative genetic studies of behavioral evolution. University of Chicago Press, Chicago

Borjesson DL, Szelistowski WA (1989) Shell selection, utilization and predation in the hermit crab Clibanarius panamensis Stimpson in a tropical mangrove estuary. J Exp Mar Biol Ecol 33:213-228

Boyero L, Barnard PC (2003) A Potamophylax larva (Trichoptera: Limnephilidae) using other caddisfly cases to construct its own case. J Nat Hist 38:1297-1301

Brönmark C, Hansson LA (2000) Chemical communication in aquatic systems: an introduction. Oikos 88:103-109

Brönmark C, Miner JG (1992) Predator-induced phenotypical change in body morphology in crucian carp. Science 258:1348-1350

Chivers DP (1998) Chemical alarm signalling in aquatic predatorprey systems: a review and prospectus. Ecoscience 5:338-352

Conover MR (1978) The importance of various shell characteristics to the shell-selection behavior of hermit crabs. J Exp Mar Biol Ecol 32:131-142

Cote IM, Reverdy B, Cooke PK (1998) Less choosy or different preference? Impact of hypoxia on hermit crab shell assessment and selection. Anim Behav 56:867-873

Dewitt TJ, Sih A, Hucko JA (1999) Trait compensation and cospecialization in a freshwater snail: size, shape and antipredator behaviour. Anim Behav 58:397-407

Dodson SI (1989) The ecological role of chemical stimuli for the zooplankton: predator-induced morphology in Daphnia. Oecologia 78:361-367

Dodson SI, Crowl TA, Peckarsky BL, Kats LB, Covich AP, Culp JM (1994) Non-visual communication in freshwater benthos: an overview. J N Am Benthol Soc 13:268-282

Englund G, Otto C (1991) Effects of ownership status, weight asymmetry, and case fit on the outcome of case contests in two populations of Agrypnia pagetana (Trichoptera: Phryganeidae) larvae. Behav Ecol Sociobiol 29:113-120

Harvell CD (1984) Predator-induced defense in a marine bryozoan. Science 224:1357-1359

Harvell CD (1990) The ecology and evolution of inducible defenses. Q Rev Biol 65:323-340

Herreid CF, Full RJ (1986) Energetics of hermit crabs during locomotion: the cost of carrying a shell. J Exp Biol 120:297308

Holomuzki JR (1983) Predatory behavior of larval Ambystoma tigrinum nebulosum on Limnephilus (Trichoptera) larvae. Great Basin Nat 43:475-476

Huryn AD, Chivers DP (1999) Contrasting behavioral responses by detritivorous and predatory mayflies to chemicals released by injured conspecifics and their predators. J Chem Ecol 25:27292740

Johansson A (1991) Caddis larvae cases (Trichoptera, Limnephilidae) as anti-predatory devices against brown trout and sculpin. Hydrobiologia 211:185-194

Johansson A, Englund G (1995) A predator-prey game between bullheads and case-making caddis larvae. Anim Behav 50:785792

Kats LB, Dill LM (1998) The scent of death: chemosensory assessment of predation risk by prey animals. Ecoscience 5: 361-394

Kohler SL, McPeek MA (1989) Predation risk and the foraging behavior of competing stream insects. Ecology 70:1811-1825

Kuhara N, Nakano S, Miyasaka H (2001) Alterations in the grazing activities of cased caddisfly larvae in response to variations in predation risk and resource level. Ecol Res 16:705-714

Lively CM (1986) Predator-induced shell dimorphism in the acorn barnacle Chthamalus anisopoma. Evolution 40:232-242

Lively CM (1988) A graphical model for shell-species selection by hermit crabs. Ecology 69:1233-1238
Malmqvist B (1992) Stream grazer responses to predator odour-an experimental study. Nord J Freshw Res 67:27-34

McCollum SA, Leimberger JD (1997) Predator-induced morphological changes in an amphibian: predation by dragonflies affects tadpole shape and color. Oecologia 109:615-621

McIntosh AR, Peckarsky BL, Taylor BW (2002) The influence of predatory fish on mayfly drift: extrapolating from experiments to nature. Freshw Biol 47:1497-1513

Mima A, Ohmori H, Wada S, Goshima S (2002) Exposure to predators affects shell preference of the hermit crab Pagurus filholi. Benthos Res 57:85-89

Molles MC Jr, Nislow KH (1991) Geographic variation in the structure of caddisfly cases: clues to the influences of competition and predation. In: Tomaszewski C (ed) Proceedings of the 6th international symposium on Trichoptera. Adam Mickiewicz University Press, Poznan, Poland, pp 177-180

Nislow KH, Molles MC Jr (1993) The influence of larval case design on vulnerability of Limnephilus frijole (Trichoptera) to predation. Freshw Biol 29:411-417

Otto C (1974) Growth and energetics in a larval population of Potamophylax cingulatus (Steph.) (Trichoptera) in a South Swedish stream. J Anim Ecol 43:339-361

Otto C (1987) Behavioural adaptations by Agrypnia pagetana (Trichoptera) larvae to cases of different value. Oikos 50:191196

Otto C (2000) Cost and benefit from shield cases in caddis larvae. Hydrobiologia 436:35-400

Otto C, Johansson A (1995) Why do some caddis larvae in running waters construct heavy, bulky cases? Anim Behav 49:473-478

Otto C, Svensson BS (1980) The significance of case material selection for the survival of caddis larvae. J Anim Ecol 49:855865

Peckarsky BL, McIntosh AR, Taylor BW, Dahl J (2002) Predator chemicals induce changes in mayfly life history traits: a wholestream manipulation. Ecology 83:612-618

Petterson LB, Brönmark C (1999) Energetic consequences of an inducible morphological defence in crucian carp. Oecologia 121:12-18

Relyea RA (2001) Morphological and behavioral plasticity of larval anurans in response to different predators. Ecology 82: 523540

Rincón PA (1993) Utilización integrada de diferentes recursos: patrones en la alimentación el uso del microhábitat de una población de trucha común (Salmo trutta L.) en el río Negro (Asturias). Ph. D. thesis, Universidad Complutense, Madrid, Spain

Rittschof D, Hazlett BA (1997) Behavioural responses of hermit crabs to shell cues, predator haemolymph and body odour. J Mar Biol Assoc UK 77:737-751

Smith RJF (1992) Alarm signals in fishes. Rev Fish Biol Fish 2:3363

StatSoft, Inc (2001) STATISTICA (data analysis software system), version 6. http://www.statsoft.com

Stevens DJ, Hansell MH, Freel JA, Monaghan P (1999) Developmental trade-offs in caddis flies: increased investment in larval defence alters adult resource allocation. Proc R Soc Lond B Biol Sci 266:1049-1054

Summey MR, Mathis A (1998) Alarm responses to chemical stimuli from damaged conspecifics by larval anurans: tests of three Neotropical species. Herpetologica 54:402-408

Tollrian R, Harvell CD (1999) The evolution of inducible defenses: current ideas. In: Tollrian R, Harvell CD (eds) The ecology and evolution of inducible defenses. Princeton University Press, Princeton, NJ and Chichester, UK, pp 306-321

Trusell GC, Nicklin MO (2002) Cue sensitivity, inducible defense and trade offs in a marine snail. Ecology 83:1635-1647

Van Buskirk J (2000) The costs of an inducible defense in anuran larvae. Ecology 81:2813-2821

Van Buskirk J, McCollum SA (1999) Plasticity and selection explain variation in tadpole phenotype between ponds with different predator composition. Oikos 85:31-39 
Van Buskirk J, McCollum SA (2000) Functional mechanisms of an inducible defence in tadpoles: morphology and behaviour influence mortality risk from predation. J Evol Biol 13:336-347

West-Eberhard MJ (1989) Phenotypic plasticity and the origins of diversity. Ann Rev Ecolog Syst 20:249-278

Wilber TP (1990) Influence of size, species and damage on shell selection by the hermit crab Pagurus longicarpus. Mar Biol 104:31-39

Wilson DJ, Lefcort H (1993) The effect of predator diet on the alarm response of red-legged frog, Rana aurora, tadpoles. Anim Behav 46:1017-1019
Wissinger SA, Whiteman HH, Sparks GB, Rouse GL, Brown WS (1999) Foraging trade-offs along a predator-permanence gradient in subalpine wetlands. Ecology 80:2102-2116

Woodward G, Hildrew AG (2002) Differential vulnerability of prey to an invading top predator: integrating field surveys and laboratory experiments. Ecol Entomol 27:732-744

Wudkevich K, Wisenden BD, Chivers DP, Smith RJ (1997) Reactions of Gammarus lacustris to chemical stimuli from natural predators and injured conspecifics. J Chem Ecol 23: $1163-1173$ 